Article

\title{
Nanotransition Materials (NTMs): Photocatalysis, Validated High Effective Sorbent Models Study for Organic Dye Degradation and Precise Mathematical Data's at Standardized Level
}

\author{
Farheen Khan ${ }^{1, *}$, Rizwan Wahab ${ }^{2,3, *}$, Mohamed Hagar ${ }^{1,4}$, Rua Alnoman ${ }^{1}$, Lutfullah ${ }^{5}$ and \\ Mohd Rashid ${ }^{6}$ \\ 1 Department of Chemistry, Faculty of Science, Taibah University, Yanbu 42353, Saudi Arabia; \\ Mohamedhaggar@gmail.com (M.E.H.); Rua-b-n@live.co.uk (R.A.) \\ 2 Department of Zoology, College of Science King Saud University, Riyadh 11451, Saudi Arabia \\ 3 Al-Jeraisy, Chair for DNA Research, Department of Zoology, College of Science, King Saud University, \\ Riyadh 11451, Saudi Arabia \\ 4 Department of Chemistry, Faculty of Science, Alexandria University, Alexandria 21321, Egypt \\ 5 Department of Chemistry, Aligarh Muslim University, Aligarh UP 202002, India; lutfullah786@gmail.com \\ 6 Saraswati Devi Post Graduate College, Khadda Bazar, Kushinagar UP 274802, India; \\ mohammadrashid87@gmail.com \\ * Correspondence: khanfarheenchem@gmail.com (F.K.); rwahab05@gmail.com (R.W.); \\ Tel.: +966-571603069 (F.K.)
}

Received: 31 December 2017; Accepted: 21 February 2018; Published: 27 February 2018

\begin{abstract}
The present work describes the synthesis of copper oxide nanoparticles (CuONPs) via a solution process with the aim of applying the nano-adsorbent for the reduction of methylene blue (MB) dye in alkaline media. These NPs were characterized via Field emission scanning electron microscopy (FE-SEM), X-ray diffraction, high-resolution Transmission electron microscopy (TEM), and ultra violet UV-visible spectroscopy to confirm their morphology and crystalline and optical properties in order to design an adsorption-degradation process. The photocatalytic $\mathrm{CuONPs}$ exhibited dynamic properties, great adsorption affinity during the chemisorption process, and operated at various modes with a strong interaction between the adsorbent and the adsorptive species, and equilibrium isotherm, kinetic isotherm, and thermodynamic activities in the presence of UV light. All basic quantities, such as concentration, $\mathrm{pH}$, adsorbent dose, time, and temperature, were determined by an optimization process. The best-fitted adsorption Langmuir model $\left(R^{2}=0.9988\right)$ and performance, including adsorption capacity $(350.87 \mathrm{mg} / \mathrm{g})$, photocatalytic efficiency $(90.74 \%)$, and degradation rate constant $\left(K \mathrm{~s}=2.23 \times 10^{-2} \mathrm{~min}^{-1}\right)$, illustrate good feasibility with respect to sorption-reduction reactions but followed a pseudo-second-order kinetic on the adsorbent surface, reaching an equilibrium point in $80 \mathrm{~min}$. The thermodynamic analysis suggests that the adsorption reaction is spontaneous and endothermic in nature. The thermodynamic parameters such as enthalpy $\left(\Delta \mathrm{H}^{\circ}\right)$, entropy $\left(\Delta \mathrm{S}^{\circ}\right)$, and Gibbs free energy $\left(\Delta \mathrm{G}^{\circ}\right)$ give effective results to support a chemical reduction reaction at $303 \mathrm{~K}$ temperature. The equilibrium isotherm and kinetic and thermodynamic models with error function analysis explore the potential, acceptability, accuracy, access to adsorbents, and novelty of an unrivaled-sorption system.
\end{abstract}

Keywords: CuONP synthesis; methylene blue (MB) dye; photocatalytic degradation; kinetic and equilibrium isotherm; thermodynamics; error analysis 


\section{Introduction}

The metal oxide nanomaterials have multidisciplinary applications in basic and applied sciences due to their large surface area, small size, higher surface lattice energy, high thermal reactivity, etc. It illustrates their beneficial purposes in processes such as adsorption, catalysis, energy conversion storage, optoelectronics, and drug delivery systems [1-6]. The nanomaterial powders are employed in industry in various ways, connecting the physicochemical, biological, engineering, and health sectors [7]. Many kinds of materials are used for the removal of dyes, via adsorption processes, from agricultural waste material, metals, organic compounds, textile wastes, etc. [8-10]. To remove organic dyes from water, various procedures have been applied but are costly and do not give effective results; the metal oxide (MO) nanomaterials (NMs) are the best alternative and the most effective material, having participated in the removal of hazardous/toxic dyes in water. The MONMs have properties that overcome the complications of removing hazardous/toxic dyes from water and the environment through reduction or degradation processes [11,12]. A series of methods have been designed for the removal of dyes, such as adsorption, ion exchange, filtration/coagulation, ozonization, Fenton reagent, photocatalytic reactions, aerobic degradation, anaerobic degradation, and biosorption. All these methods belong to three categories: physical, chemical, and biological methods. In comparison to all these methods, the adsorption method is the most popular, most effective, simplest, cheapest, and is a routinely used technique on larger application scales. Generally, adsorption techniques provide selective and easy-to-use sorbents and cleanup medium, are simple, and have easy sample preparations for the isolation/removal of toxic substances. These reasons and its small risk of errors are the main advantages of adsorption techniques, which are traditionally used in laboratories. As per scientific depiction, adsorption processes follow equilibrium and kinetics processes; both processes provide simultaneous advantage: first, the kinetic rate of the reaction of the overall adsorption mechanism and second, adsorption-desorption equilibrium analysis performance at equivalent, stable and constant time in the presence of all optimized parameters. In the adsorption system, the fitness of the four kinetic models (Lagergren pseudo-first-order, Ho and McKay pseudo-second-order, Elovich model, and intraparticle diffusion) and the four equilibrium isotherm models (Freundlich, Langmuir, Dubinin-Radushkevich, and Temkin) are based on linear regression methods that correspond to the feasibility of a nanomaterial system combined with methylene blue (MB) ions on the adsorbent's surface $[13,14]$. Various types of engineered nanoparticles, such as zinc, magnesium, iron, aluminum oxide, cerium oxide, and zirconium oxide, are being extensively utilized for the removal of organic wastes [15]. Other versatile nanostructures of $\mathrm{MOs,}$ the $\mathrm{CuO}$ nanostructures, which arise in the d-block transition metal series, have unique properties (such as catalytic, antimicrobial, and antifungal) and various applications (such as in industry, electronics, optoelectronics, sensors, and biomedical applications). The requirement to clean, freshen, and save the environment from organic carcinogenic compounds, dyes and more hazardous environmental contaminants [16,17] can be aided via photocatalytic CuONMs [18]. CuO has various physical properties, such as p-type semiconductor, an energy band gap of 1.21-1.5 eV, and good quantum efficiency. It has been tested as a photocatalyst for the deactivation of organic molecules/dyes, which it decomposes or deactivates mainly via a photocatalytic process that is more impulsive under UV-visible light [19]. Numerous physicochemical methods can be applied to synthesize the nanostructures of copper, such as plasma-enhanced chemical vapor deposition (PECVD), surface mechanical attrition treatment (SMAT), chemical vapor deposition (CVD), metal-organic chemical vapor deposition (MO-CVD), etc. The chemical methods such as solution, sol-gel, hydrothermal, combustion, and spray pyrolysis [20-25] can provide large quantities of nanostructures. Organic dyes are highly hazardous to the human body and cause a series of diseases, such as hypertension, precordial pain, mental confusion, nausea, profuse sweating, methemoglobinemia, skin staining, dizziness, headache, Alzheimer, anemia, and eye-burn problems [26-31]. To solve this problem and for a healthy environment, it is very important to understand and study the toxic substances (dyes) and their relations with biological species [32-35]. Toward this goal, several parameters have been 
applied (such as the concentration of dye, duration of toxic effects, control dyes, and applied technique) to regulate their toxic effects; therefore, from the fitness consideration of these points, the analytical technique is fully able to detect, identify, quantify toxic dyes and organic substances [33,34]. Due to its fast, simple, and cheap methodology, it provides satisfactory results for colored and colorless routine laboratory samples analyzed via UV-visible spectrophotometer [36]. A few amount of nanomaterials has the capability to degrade organic dyes into small fragments and can remove the pollution $[32,33,36]$. Different types of copper precursors (such as copper nitrate hexahydrate, copper chloride, and copper sulfate) have been utilized to degrade methylene blue (MB) and rhodamine $\mathrm{B}(\mathrm{RhB})$ dyes in an aqueous solution [37]. In another report, including the nanoparticles, the polymer nanocomposites (chitosan/polyvinyl alcohol/copper oxide nanorods, CS/PVA/CuO) were utilized as an adsorbent for the removal of $\mathrm{Pb}$ (II) ions from an aqueous environment [38]. In this continuation, the inorganic nanocomposite of $(\mathrm{CuO} / \mathrm{MCM}-41$ nano composite) $\mathrm{CuO}$, which exhibits a high potential in the treatment of wastewater [14], was used as an adsorbent for the removal of cationic dyes. Towards this direction, researchers have done and explained the adsorption capacity of different types of nanomaterials (NMs) for the removal of heavy metals and dyes [39-42] and have employed and discussed the adsorption capacity, efficiency, isotherms, and kinetic parameters.

The thermodynamic parameters $\left(\Delta \mathrm{H}^{\circ}, \Delta \mathrm{G}^{\circ}, \Delta \mathrm{S}^{\circ}\right.$, and $\left.\Delta \mathrm{E}^{\circ}\right)$ and kinetic models give more detail about the consequences of NMs. The thermodynamic and kinetic studies describe better the relationship between NMs and other chemical species with good adherence or adsorption properties. An adsorption kinetic study performed in an aqueous solution with constant temperature provides valuable information related to the fixed number of sites on the adsorbent and the adsorbate material. To evaluate the consequences of dyes in wastewater, various technologies have been applied: biological, chemical, and physical. These methods are very useful for environmental purification. As per the detailed literature survey, various adsorption studies have been performed for organic, inorganic, hybrid, and composite materials, which have included isotherm, kinetics, thermodynamic studies for assessing the adsorption and desorption. Basically, a heterogeneous system favors adsorption techniques, which require more than one ingredient, provide suitability and efficiency and easily adopt the study of equilibrium and kinetics [39-42].

The present work describes first the synthesis of copper oxide nanoparticles, referred to as CuONPs, using a solution process, and then the characterization of CuONPs using XRD (X-ray diffraction pattern), FE-SEM (Field emission scanning electron microscopy), and TEM (Transmission electron microscopy). Besides this, the main objective of our work is to investigate the parameters that influence the initial solution $\mathrm{pH}$, adsorbent dose, initial MB dye concentration, and temperature. The study provides information related to collective results such as kinetic sorption study analyses via pseudo-first- and second-order, Elovich model and intraparticle diffusion mechanism (IPDM). The equilibrium study was better fitted to the Langmuir and Freundlich models than the Hasley, H-J, Temkin, and D-R models. The thermodynamic study of the heat of adsorption at a constant temperature gives the values of the thermodynamic parameters $\left(\Delta \mathrm{H}^{\circ}, \Delta \mathrm{G}^{\circ}, \Delta \mathrm{S}^{\circ}, \Delta \mathrm{E}^{\circ}\right)$. Also evaluated and included here are the different error analyses: the residual root mean square error (RMSE), the Chi-square test, sum of the squares of the error (SSE), sum of absolute error (SAE), average relative error (ARE), average percentage errors (APE), and Marquardt's percent standard deviation (MPSD) [43].

\section{Materials and Methods}

\subsection{Formation of Copper Oxide Nanoparticles (CuONPs)}

The formation of copper oxide nanoparticles (CuONPs) was performed with the use of precursor copper nitrate hexahydrate $\left(\mathrm{Cu}\left(\mathrm{NO}_{3}\right)_{2} \cdot 6 \mathrm{H}_{2} \mathrm{O}\right)$, n-propylamine $\left(\mathrm{C}_{2} \mathrm{H}_{5} \mathrm{CH}_{2} \mathrm{NH}_{2}\right)$, surfactant CTAB (cetyltrimethylammonium bromide), and sodium hydroxide $(\mathrm{NaOH})$. All chemicals for the preparation of NPs were purchased from Aldrich Chemical Corporation based in Riyadh, Saudi Arabia and used as 
received from the company without further purification. In a typical experiment, $15 \mathrm{mM}$ copper nitrate hexahydrate $(\sim 0.4425 \mathrm{~g})$ was mixed in $100 \mathrm{~mL}$ methanol $(\mathrm{MeOH})$ under constant stirring. The soluble mixture appeared blue in color in a beaker after mixing. To this alcoholic mixture, n-propylamine $(20 \mathrm{~mL})$ was added slowly and was dissolved in methanol $(\mathrm{MeOH})$ under continuous stirring at room temperature. A small amount of surfactant CTAB (cetyltrimethylammonium bromide) (5 mg) was added to this solution, which was again mixed. The solution was stirred for $30 \mathrm{~min}$ to complete the dissolution. To this solution, alkali sodium hydroxide $(\mathrm{NaOH})$ was added gradually, drop by drop; this mixture was shaken each time for complete mixing. After complete mixing, the solution $\mathrm{pH}$ was checked via a pH meter (Cole Parmer, Bunker Court Vernon Hills, IL, USA). Due to the addition of alkali $\mathrm{NaOH}$, the basicity of the solution increased and reached $\mathrm{pH}$ 12.06. After complete mixing, the solution was transferred to a two-necked refluxing pot and refluxed at $65^{\circ} \mathrm{C}$ for $2 \mathrm{~h}$. As the solution temperature rose, the blue color of the solution changed to a dark brown color and then turned black. After the refluxing was complete, the precipitate of the formed product settled at the bottom of the refluxing pot. The formed precipitate was washed several times with alcohol (methanol $(\mathrm{MeOH})$ and ethanol $(\mathrm{EtOH})$ ) and acetone to remove the ionic impurities and then dried at room temperature. The dried powder was examined in terms of its structural and chemical properties.

\subsection{Characterization of the Prepared $\mathrm{CuONPS}$}

The general morphology of the synthesized CuONPs was examined via field emission scanning electron microscopy (FE-SEM, Hitachi S-4700, Tokyo, Japan) at room temperature. For the detailed observation by FE-SEM, the dried powder was uniformly scattered on carbon tape and coated/sputtered with a thin conducting layer of platinum $(\mathrm{Pt})$ for $3 \mathrm{~s}$. For clarification related to the morphology of the prepared NPs, the powder was again analyzed with TEM (JEOL JEM JSM 2010 at $200 \mathrm{kV}$, Tokyo, Japan). For TEM observation, nano-ranged powder was sonicated in ethanol for $10 \mathrm{~min}$ and a copper grid (carbon coated 400 mesh, Aldrich Chemical Corporation, Branch based in Riyadh, Saudi Arabia) was dipped into this solution. The copper grid was dried at room temperature and analyzed for further morphological observation. The X-ray diffraction (XRD, Rigaku, Tokyo, Japan pattern was utilized to know the particle size, phase and crystalline property of the precipitated material in the range from $20^{\circ}-65^{\circ}$ in $\mathrm{Cu}_{\mathrm{K} \alpha}$ radiation $\left(\lambda=1.54178 \AA\right.$ ) with $6^{\circ} / \mathrm{min}$ scanning speed with an accelerating voltage of $40 \mathrm{kV}$ and current of $40 \mathrm{~mA}$. For the formation of NPs, various chemicals were involved for the synthesis of the NPs.

\subsection{Photocatalytic Activity of Synthesized CuONPs}

The photocatalytic degradation of MB dye in the presence of CuONPs was carried out in a homemade photocatalytic glass reactor as per previously described work $[1,5,32,33]$. To know the detailed photocatalytic degradation of MB dye, about $5 \mathrm{mg}$ of the prepared CuONPs was added to $1 \times 10^{-5} \mathrm{M}$ of $\mathrm{MB}$ dye solution in $100 \mathrm{~mL}$ distilled water under continuous stirring. The blank or control experiment was also included to show that no other reaction happened in the absence of UV light. In our experiment, the CuONPs and MB dye solution sample $(5 \mathrm{~mL})$ were extracted each time to remove the catalyst by ultracentrifugation ( $3000 \mathrm{rpm} / \mathrm{min}$ for $5 \mathrm{~min}$, FLETA 5 , Hanil Sciind. Co., Ltd., Gimpo, South Korea) before recording the UV-visible data. The light was exposed on a home made reactor and the UV-visible data was collected at regular intervals $(0,10,20,30,40,50$, and $60 \mathrm{~min})[1,5,32,33]$.

\subsection{Adsorption Procedure}

To perform the adsorption process, a conical flask (100 mL) was used for the MB dye with $\mathrm{CuONPs}$ under ambient conditions. Different concentration ranges from 51.17 to $153.52 \mathrm{ppm}$ of MB dye was selected for the experiment. The selected amount of adsorbent ( $\sim .10 \mathrm{~g}$ of CuONPs) was added to the MB dye solution concentration under constant stirring at $90 \mathrm{rpm}$ and $303 \mathrm{~K} \mathrm{at} \mathrm{pH} 12.0$ for $1 \mathrm{~h}$ to reach its equilibrium point. The optimized/experimental solution was used at regular time 
intervals. The sample (dye and adsorbent) was completely mixed, centrifuged (10 min), and the filtrate was collected. The effect of parameters such as $\mathrm{pH}$, time, temperature, adsorbent dose, and dye concentration, were checked in solution phase. The concentrations of MB dye solution were analyzed using a UV-vis spectrophotometer (Shimadzu, Japan, UV-2555) at maximum wavelength (570 nm) and the equilibrium point was calculated by the following expression:

$$
q_{t}=\frac{\left(C_{0}-C_{t}\right) \times V}{\mathrm{~m}}
$$

where $q_{t}\left(\mathrm{mg} \cdot \mathrm{g}^{-1}\right)$ is the amount of adsorbed dye per gram of adsorbent, $C_{0}(\mathrm{ppm})$ and $C_{t}(\mathrm{ppm})$ are the concentration in solution at time $t=0$ and at time $t, V$ is the volume of the solution $(\mathrm{L})$ and ' $m$ ' is the mass of the adsorbent $(\mathrm{g})$.

\subsubsection{Effect of $\mathrm{pH}$ on $\mathrm{MB}$ Dye Adsorption}

The $\mathrm{pH}$ range of the buffer solution was optimized and chosen for all the sorption experiments. The different pHs $(8,10$, and 12) were applied for the prepared nano-adsorbent in solution form. During the adsorption process, the MB dye uptake by the nano-adsorbent was performed in a conical flask, shaken and rotated at $90 \mathrm{rpm}$ in a water bath with varying temperatures. After centrifugation, the samples were decanted at different time intervals during the equilibrium time period.

\subsubsection{Effect of MB Dye Concentration on Adsorption}

Different concentrations (51.17, 102.35, 128.0, and $153.52 \mathrm{ppm}$ ) of MB dye were chosen to investigate the effect of concentration of $\mathrm{MB}$ dye on the sorption by the nano-adsorbent material. The observed data were defined as the sorption capacity of the adsorbent $\left(q_{t}\right)$ versus time $(t)$. The concentration of dye increased in the solution with increased sorption at a constant temperature.

\subsubsection{Effect of Adsorbent Dose}

The specific amount of nanomaterials used as the adsorbent in the sorption process was selected on quantity levels. Varying the quantity was to designate the skill of the adsorbent dose ( 0.01 to $0.20 \mathrm{~g})$ to maximally adsorb the MB dye. As well, an increased dose of nano-adsorbent was used to increase the rate of adsorption of $\mathrm{MB}$ molecules at a constant temperature. After the optimization process, $0.10 \mathrm{~g}$ of adsorbent was fixed for the adsorbate at equilibrium phase.

\subsubsection{Effect of Temperature on Adsorption}

In the sorption processes, the effect of temperature on the adsorption of $\mathrm{MB}$ dye by the nano-adsorbent was evaluated in the equilibrium phase. A range of temperatures $(298,301$, and $303 \mathrm{~K})$ was checked with the mixed ingredients of $0.10 \mathrm{~g}$ adsorbent and $153.52 \mathrm{ppm}$ adsorbate at $90 \mathrm{rpm}$ and a constant $\mathrm{pH}$ of 12 for $80 \mathrm{~min}$. An increased temperature increased the rate of absorption of the absorptive species in a respective manner.

\subsection{Error Analysis}

The analysis of error is to identify an experimental sample solution that reveals adequate results. A minimized value of precision and accuracy provides good experimental error-free data. Hence, appropriate results are monitored from the linearization of isotherm parameters, which observe various regretting error conditions at constant temperature [44-48].

Residual root mean square error (RMSE):

$$
\mathrm{RMSE}=\sqrt{\frac{1}{N-2} \sum_{i=1}^{N}\left(q \mathrm{e}_{\mathrm{exp}}-q \mathrm{e}_{\mathrm{cal}}\right)^{2}}
$$


The Chi-square test:

$$
x^{2}=\sum_{i=1}^{N}\left|\frac{\left(q \mathrm{e}_{\mathrm{exp}}-q \mathrm{e}_{\mathrm{cal}}\right)^{2}}{q \mathrm{e}_{\mathrm{cal}}}\right| i
$$

The sum of the squares of the errors (SSE):

$$
\mathrm{SSE}=\sum_{i=1}^{N}\left(q \mathrm{e}_{\mathrm{cal}}-q \mathrm{e}_{\mathrm{exp}}\right)^{2}
$$

The average relative error (ARE):

$$
\mathrm{ARE}=\sum_{i=1}^{N}\left|\frac{\left(q \mathrm{e}_{\mathrm{exp}}-q \mathrm{e}_{\mathrm{cal}}\right)}{q \mathrm{e}_{\mathrm{exp}}}\right| i
$$

The sum of the absolute errors (SAE):

$$
\mathrm{SAE}=\sum_{i=1}^{N}\left(q \mathrm{e}_{\mathrm{cal}}-q \mathrm{e}_{\mathrm{exp}}\right)
$$

The average percentage errors (APE):

$$
\mathrm{APE}=\sum_{i=1}^{N}\left|\frac{q \mathrm{e}_{\mathrm{exp}}-q \mathrm{e}_{\mathrm{cal}} / q \mathrm{e}_{\mathrm{exp}}}{N}\right| \times 100
$$

Marquardt's percent standard deviation (MPSD):

$$
\operatorname{MPSD}=100 \sqrt{\frac{1}{N-P} \sum_{i=1}^{N}\left(\frac{q \mathrm{e}_{\exp }-q \mathrm{e}_{\mathrm{cal}}}{q \mathrm{e}_{\exp }}\right)_{i}^{2}}
$$

\subsection{Equilibrium Isotherm Experiment}

In this experiment, $0.10 \mathrm{~g}$ nano-adsorbent material and $153.52 \mathrm{ppm} \mathrm{MB}$ dye were added to each conical flask and the suspensions were mixed at $90 \mathrm{rpm}$ in a shaker bath at a constant $\mathrm{pH}$ of 12 for $80 \mathrm{~min}$. After that, the various concentrations of dye solution that had adsorbed onto the sorbent surface were cautiously determined by a titrimetric technique in solution phase [49-55].

\subsubsection{Kinetic Model}

The MB dye was adsorbed onto the surface of the nano-adsorbent, showing maximum affinity toward the ions in solution phase. The kinetic models such as Lagergren's pseudo-first-order kinetic model, Ho and McKay pseudo-second-order kinetic model, Elovich model, and intraparticle diffusion were supported and the control nano-adsorbent-dye reaction mechanism was performed at varying concentrations of $\mathrm{MB}$ dye solution ( $\mathrm{ppm}$ ) at different temperatures (K). The equations of the kinetic models are set in experimental data and obtained best-fit results with a good agreement [56-58].

\subsubsection{Thermodynamic Study}

To investigate the optimized thermodynamic parameters of the chemically synthesized nano-adsorbent used as the adsorbent for the sorption of MB dye, the CuONPs were employed with the dye (MB, $153.52 \mathrm{ppm})$ in a specialized conical flask and the solution was mixed under stirring. Thereafter, it was separated via centrifugation. After the parameters were optimized, the uptake amount of MB dye at equilibrium $q_{e}\left(\mathrm{mg} \cdot \mathrm{g}^{-1}\right)$ was evaluated and calculated [57]. 


\subsubsection{Lagergren's Pseudo-First-Order Kinetics}

The pseudo-first-order equation is generally expressed as follows:

$$
d_{\frac{q_{t}}{d t}}=K_{\mathrm{F}}\left(q_{\mathrm{e}}-q_{t}\right)
$$

where $q_{t}$ is the amount of adsorbate adsorbed $\left(\mathrm{mg} \cdot \mathrm{g}^{-1}\right)$ at time $t, q_{\mathrm{e}}$ is the adsorption capacity at equilibrium $\left(\mathrm{mg} \cdot \mathrm{g}^{-1}\right), K_{\mathrm{F}}$ is the pseudo-first-order rate constant $\left(\mathrm{min}^{-1}\right)$, and " $t$ " is the contact time (min). Integrating Equation (1) with the initial condition $q_{t}=0$ at $t=0$ and $q_{t}=q_{t}$ at $t=t$, the equation becomes:

$$
\log \left(q_{\mathrm{e}}-q_{t}\right)=\log q_{\mathrm{e}}-\frac{K_{\mathrm{F}} t}{2.303}
$$

A plot of $\log \left(q_{\mathrm{e}}-q_{t}\right)$ versus time $t$ gives the values of $K_{\mathrm{F}}$ and $q_{\mathrm{e}}$ from the slope and intercept, respectively.

\subsubsection{Ho and McKay Pseudo-Second-Order Kinetic Model}

The pseudo-second-order model is represented as:

$$
d_{\frac{q_{\mathrm{t}}}{d t}}=K_{\mathrm{s}}\left(q_{\mathrm{e}}-q_{t}\right)^{2}
$$

where $K_{\mathrm{s}}$ is the pseudo-second-order rate constant $\left(\mathrm{g} \cdot \mathrm{mg}^{-1} \cdot \mathrm{min}^{-1}\right)$. Integrating Equation (4) and applying the boundary conditions $q_{t}=0$ at $t=0$ and $q_{t}=q_{t}$ at $t=t$, the equation becomes:

$$
\frac{t}{q_{t}}=\frac{1}{K_{\mathrm{s}} q_{\mathrm{e}}^{2}}+\left(\frac{1}{q_{\mathrm{e}}}\right) t
$$

A plot of $t / q_{t}$ versus $t$ gives the values of the pseudo-second-order constant $K_{\mathrm{s}}\left(\mathrm{g} \cdot \mathrm{mg}^{-1} \cdot \mathrm{min}^{-1}\right)$ and $q_{\mathrm{e}}\left(\mathrm{mg} \cdot \mathrm{g}^{-1}\right)$. The initial sorption rate $h\left(\mathrm{mg} \cdot \mathrm{g}^{-1} \cdot \mathrm{min}^{-1}\right)$ at $t \rightarrow 0$ is defined as:

$$
h=K_{\mathrm{s}} q_{\mathrm{e}}^{2}
$$

From Equations (4) and (5), we get the following new equation:

$$
\frac{t}{q_{t}}=\frac{1}{h}+\left(\frac{1}{q_{\mathrm{e}}}\right) t
$$

The initial sorption rate $h$ is obtained from the intercept since $q_{\mathrm{e}}$ is known from the slope; the second-order rate constant $K_{\mathrm{s}}$ can be determined from the value of $h$.

\subsubsection{The Elovich Equation}

This equation was validated via chemisorption and it covers the extensive absorptions sites. The equation is as follows:

$$
\frac{d q_{t}}{d_{t}}=\alpha e^{-\beta q_{t}}
$$

Integrating this equation for the boundary conditions gives:

$$
q_{t}=\frac{1}{\beta} \ln (\alpha \beta)+\frac{1}{\beta} \ln t
$$

where $\alpha\left(\mathrm{mg} \cdot \mathrm{g}^{-1} \cdot \mathrm{min}^{-1}\right)$ is the initial sorption rate and $\beta\left(\mathrm{g} \cdot \mathrm{mg}^{-1}\right)$ is related to the extent of surface coverage and the activation energy involved in the chemisorption. 


\subsubsection{Intraparticle Diffusion Equation (IDE)}

The IDE is as follows:

$$
q_{t}=K_{\mathrm{id}} \cdot t^{1 / 2}+I
$$

where $K_{\mathrm{id}}\left(\mathrm{mg} \cdot \mathrm{g}^{-1} \cdot \mathrm{min}^{-1 / 2}\right)$ is the intraparticle diffusion rate constant. A plot of $q_{t}$ versus $t^{1 / 2}$ presents the adsorption of dye onto the adsorbent. Values of $I$ give an idea of the thickness of the boundary layer; that is, the larger the intercept, the greater is the boundary layer effect.

\subsection{Equilibrium Isotherm Models}

Isotherm models represent the relationship between the concentration of the adsorbate (MB dye) solution in parts per million (ppm) and the amount of dye adsorbed. To evaluate this, various chemical equations were applied, such as Freundlich, Langmuir, Dubinin-Radushkevich, and the Temkin isotherm, to define the equilibrium features of adsorption.

\subsubsection{The Langmuir Adsorption Isotherm}

The Langmuir adsorption isotherm is represented by the following equation:

$$
\frac{1}{q_{\mathrm{e}}}=\left(\frac{1}{K_{\mathrm{L}} q_{m}}\right) \frac{1}{\mathrm{C}_{\mathrm{e}}}+\frac{1}{q_{m}}
$$

where $C_{\mathrm{e}}(\mathrm{ppm})$ and $q_{\mathrm{e}}\left(\mathrm{mg} \cdot \mathrm{g}^{-1}\right)$ are the equilibrium concentrations in the liquid and solid phases, respectively; $K_{\mathrm{L}}$ and $q_{m}$ are the Langmuir constants. $q_{m}$ expresses the maximum adsorbent uptake $\left(\mathrm{mg} \cdot \mathrm{g}^{-1}\right)$ and $K_{\mathrm{L}}$ is related to the energy of adsorption and affinity of the sorbent. The value of $q_{m}$ and $K_{\mathrm{L}}$ can be calculated from the plot of $1 / q_{\mathrm{e}}$ versus $1 / C_{\mathrm{e}}$. A further analysis of the Langmuir equation can be made on the basis of a dimensionless equilibrium parameter $R_{\mathrm{L}}$, also known as the separation factor:

$$
R_{\mathrm{L}}=\frac{1}{1+K_{\mathrm{L}} \mathrm{C}_{0}}
$$

where $K_{\mathrm{L}}$ is the Langmuir constant and $C_{0}$ is the initial metal ion concentration (ppm). It gives favorable adsorption when $0<R_{\mathrm{L}}<1$.

\subsubsection{Freundlich Adsorption Isotherm}

The Freundlich adsorption isotherm can be represented by the following equation:

$$
\ln q_{\mathrm{e}}=\ln K_{\mathrm{F}}+\frac{1}{n}\left(\ln C_{\mathrm{e}}\right)
$$

where $q_{\mathrm{e}}$ is the metal ion adsorbed at equilibrium time, $C_{\mathrm{e}}$ is the equilibrium concentration of CuONPs in solution, $K_{\mathrm{F}}\left(\mathrm{L} \cdot \mathrm{g}^{-1}\right)$ and $n$ are Freundlich constants characteristics of the system and indicating the adsorption capacity and adsorption intensity, respectively. The isotherm constant can be calculated from the intercept and slope of a plot of $\ln q_{\mathrm{e}}$ versus $\ln C_{\mathrm{e}}$.

\subsubsection{Dubinin-Radushkevich Adsorption Isotherm}

The Dubinin and Radushkevich or D-R equation is written as follows:

$$
\ln q_{\mathrm{e}}=\ln q_{m}-\beta \mathrm{e}^{2}
$$

where $q_{m}$ is the $\mathrm{D}-\mathrm{R}$ constant and $\varepsilon$ is correlated to temperature as follows:

$$
\mathrm{e}=R T \ln \left(1+\frac{1}{C_{\mathrm{e}}}\right)
$$


The constant $\beta$ gives the mean free energy $E$ of sorption per molecule of sorbate when it is transferred to the surface of a solid from the bulk solution and can be computed using the following relationship:

$$
E=1 / \sqrt{2 \beta}
$$

The graph is plotted as $\ln q_{\mathrm{e}}$ versus $\mathrm{e}^{2}$. The value of $\beta$ and $q_{m}$ are calculated from the slope and intercept, respectively.

\subsubsection{Temkin Isotherm}

This isotherm has influences and it clearly takes into consideration the adsorbing speciesadsorbent interactions.

The Temkin isotherm is given as follows [43]:

$$
q_{\mathrm{e}}=\frac{R T}{b} \ln \left(K_{T} C_{\mathrm{e}}\right) \text { or } B_{1} \ln K_{T}+B_{1} \ln C_{\mathrm{e}}
$$

where

$$
B_{1}=\frac{R T}{b}
$$

A plot of $q_{\mathrm{e}}$ versus $\ln C_{\mathrm{e}}$ enables the determination of isotherm constants $B_{1}$ and $K_{T}$ from the slope and intercept, respectively. ' $R$ ' is the gas constant, ' $b$ ' is Temkin constant, $K_{T}$ is the equilibrium binding constant $\left(\mathrm{L} \cdot \mathrm{g}^{-1}\right)$ corresponding to the maximum binding energy. The constant $B_{1}$ is related to the heat of adsorption.

\subsubsection{Harkins-Jura Isotherm}

The multilayer adsorption and the existence of heterogeneous pore distribution in the surface of the adsorbent are mainly described by the Harkins-Jura isotherm model, which is expressed as

$$
\frac{1}{q_{\mathrm{e}}^{2}}=\frac{B_{\mathrm{HJ}}}{A_{\mathrm{HJ}}}-\frac{1}{A_{\mathrm{HJ}}} \log C
$$

where $A_{\mathrm{HJ}}$ and $B_{\mathrm{HJ}}$ are Harkins-Jura constants. The value of $A_{\mathrm{HJ}}$ and $B_{\mathrm{HJ}}$ are determined from the slope and intercept, respectively, of the plot of $1 / q_{\mathrm{e}}^{2}$ versus $\log C_{\mathrm{e}}$.

\subsubsection{Hasley Isotherm Model}

Hasley isotherm can be used to evaluate the multilayer adsorption process at a relatively large distance from the surface. The model can be expressed as:

$$
\ln q_{\mathrm{e}}=\frac{1}{n_{\mathrm{H}}} \ln \mathrm{K}_{\mathrm{H}}-\frac{1}{n_{\mathrm{H}}} \ln \left(\frac{1}{C_{\mathrm{e}}}\right)
$$

where $n_{\mathrm{H}}$ and $K_{\mathrm{H}}$ are the Hasley constants, which can be determined from the slope and intercept of the linear plot based on $\ln q_{\mathrm{e}}$ versus $\ln \left(1 / C_{\mathrm{e}}\right)$.

\subsection{Thermodynamic Study}

The change in Gibbs free energy for the adsorption is related to the equilibrium constant by the classic van't Hoff equation:

$$
\Delta G=-R T \ln K
$$

This Gibbs free energy change is directly related to the entropy change adsorption heat at constant temperature and can be presented as follows:

$$
\Delta G=\Delta H-T \Delta S
$$




$$
\log \frac{q_{e}}{C_{e}}=\frac{\Delta S}{2.303 R}+\left(\frac{-\Delta H}{2.303 R T}\right)
$$

where $q_{\mathrm{e}}$ is the dye adsorbed $\left(\mathrm{mg} \cdot \mathrm{g}^{-1}\right), C \mathrm{e}$ is the equilibrium concentration (ppm), $T$ is the temperature (Kelvin), and $q_{\mathrm{e}} / C_{\mathrm{e}}$ is called the adsorption affinity. The above equation is for unit mass of adsorbent dose.

\section{Results and Discussion}

\subsection{Structural Morphological Description of Prepared CuONPs (FE-SEM and TEM Results)}

The general structural morphology of the chemically prepared NPs was investigated under FE-SEM and the obtained images are presented in Figure 1A,B. From the images, it is visualized that the NPs are in an aggregated Figure 1A form with several fine NPs. When the prepared NPs are viewed at high resolution Figure 1B, it is confirmed that the prepared material is in the nanoscale range and present in a very large quantity. The obtained fine powdery material is spherical in shape and exhibits an average size of $\sim 10-15 \mathrm{~nm}$. Several fine nano-scaled particles are seen in the images; some are spherical and some are in aggregated form. From the image, the surfaces of the NPs are smooth, clean and spherical in structure Figure 1A. Another FE-SEM image Figure 1C shows the adsorption of methylene blue (MB) dye molecules. After the adsorption of MB dye, the image clearly shows that the NPs are joined with each other and form aggregated nanostructures due to the adsorption of organic dye molecules. Further investigation related to structural morphology of the prepared NPs was performed via TEM at room temperature with an accelerating voltage at $200 \mathrm{kV}$. From the obtained image, it is evident that the small NPs are gathered together and have fine particles in an aggregated form Figure 1D. The diameter of each NP is in the range of $\sim 10-15 \mathrm{~nm}$, is spherical, smooth, and clearly consistent with the observation from FE-SEM Figure 1A,B. The high-resolution TEM image shows that each particle is crystalline in nature, is uniform in size and shape, and has crystalline properties Figure 1E. The HR-TEM image shows the lattice space between two fringes to be $\sim 0.233 \mathrm{~nm}$ Figure 1E, which corresponds to the " $\mathrm{d}$ " value of the (111) facets of $\mathrm{CuO}$ crystals, marked in white lines and arrows in the TEM picture of the CuONPs [59-61]. The obtained image is clearly consistent with the FE-SEM observation (Figure 1A,B) [59-61].

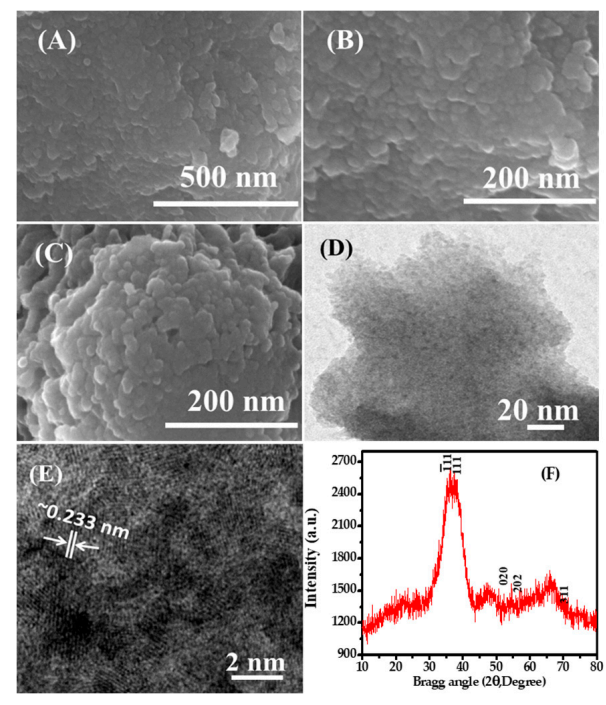

Figure 1. Field emission scanning electron microscopy (FE-SEM) images of copper oxide nanoparticles (CuO NPs): (A) NPs at low magnification and (B) high magnification; (C) After the adsorption of NPs; (D) TEM images of CuO NPs at low magnification; (E) HR-TEM images of NPs with lattice fringes about $\sim 0.233 \mathrm{~nm}$ apart and showing the " $\mathrm{d}$ " value of the (111) of CuO NPs; (F) X-ray diffraction pattern of grown copper oxide NPs. 


\subsection{X-ray Diffraction Spectroscopy (XRD)}

The phase, size, and crystalline property of the synthesized (grown) nano-powder were analyzed via $\mathrm{XRD}$ at the above parameters. Figure $1 \mathrm{~F}$ shows a broad peak width, which easily affirms that the size of the grown particles is very small and that the nano-powder has a single crystalline character of $\mathrm{CuO}$ without any chemical impurities. It is also well matched with the standard JCPDS data card no. 05-661. The diffraction peaks in the XRD pattern observed at the diffraction reflections appear at $35.55^{\circ}$ (I11), $38.80^{\circ}(111), 53.95^{\circ}(020), 58.40$ (202), and $72.40^{\circ}$ (311), respectively, which show the XRD spectrum for the formed $\mathrm{CuO}$ nanostructures (Figure 1F). The wider width of the peaks clearly shows that the size of the grown nanoparticles is very small. The XRD spectrum shows only peaks related to $\mathrm{CuO}$, without any other impurities or anything other than $\mathrm{CuO}$, which further confirms that the grown powder is pure $\mathrm{CuO}$ (Figure 1F).

\subsection{Catalytic Assessment of CuONPs in the Presence of UV Light}

To examine the catalytic sorption/degradation activity in the presence of MB dye under the employed nanomaterial (CuONPs), the initial UV-visible spectroscopy was analyzed with the blank solution of MB dye and thereafter NPs with MB dye Figure 2A. The acquired results show the reduction properties of NPs against MB dye under UV (ultra violet) wave lengths Figure 2B. For further elucidation, kinetic reactions were applied and they follow first-order and reaction rate kinetics as previous Figure 2C [3,4]. The rate constant of CuONPs and MB dye is $2.23 \times 10^{-2} \mathrm{~min}^{-1}$ and the photocatalytic efficiency is $90.74 \%$.
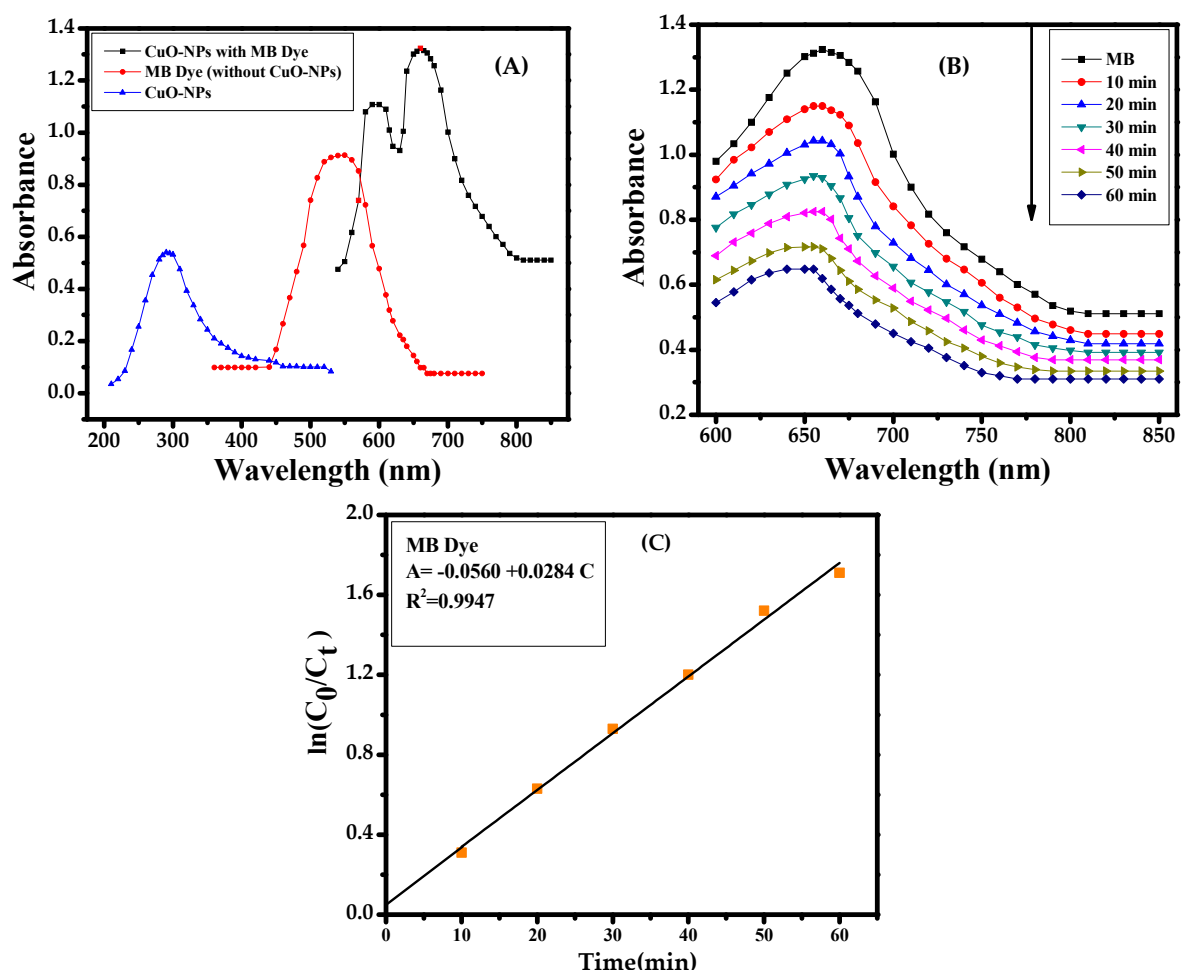

Figure 2. (A) UV spectra of methylene blue (MB) dye with CuONPs; (B) catalytic reduction of MB dye with $\mathrm{CuONPs}$ and $(\mathrm{C})$ calibration plot of $\ln \left(C_{0} / C_{t}\right)$ vs. time for the photodegradation of MB dye.

\subsubsection{Effect of $\mathrm{pH}$}

The great impact of $\mathrm{pH}$ on the adsorbent surface encourages the ionization of molecules or the diffusion of ions/functional groups on the active sites of the CuONPs adsorbent, maintaining the surface charge during the adsorption process. The variable $\mathrm{pH}(8,10,12)$ of the solutions was used 
in the sorption process and enhanced the sorption activity in a basic medium with $\mathrm{pH}$ 12.0. It can be seen in Figure 3A that the maximum and constant adsorption value was found at $\mathrm{pH}$ 12.0. An increase in $\mathrm{pH}$ increases the sorption capacity that reached a maximum point at 80 min Figure $3 \mathrm{~A}$, which is suitable and was selected for the overall experiments.
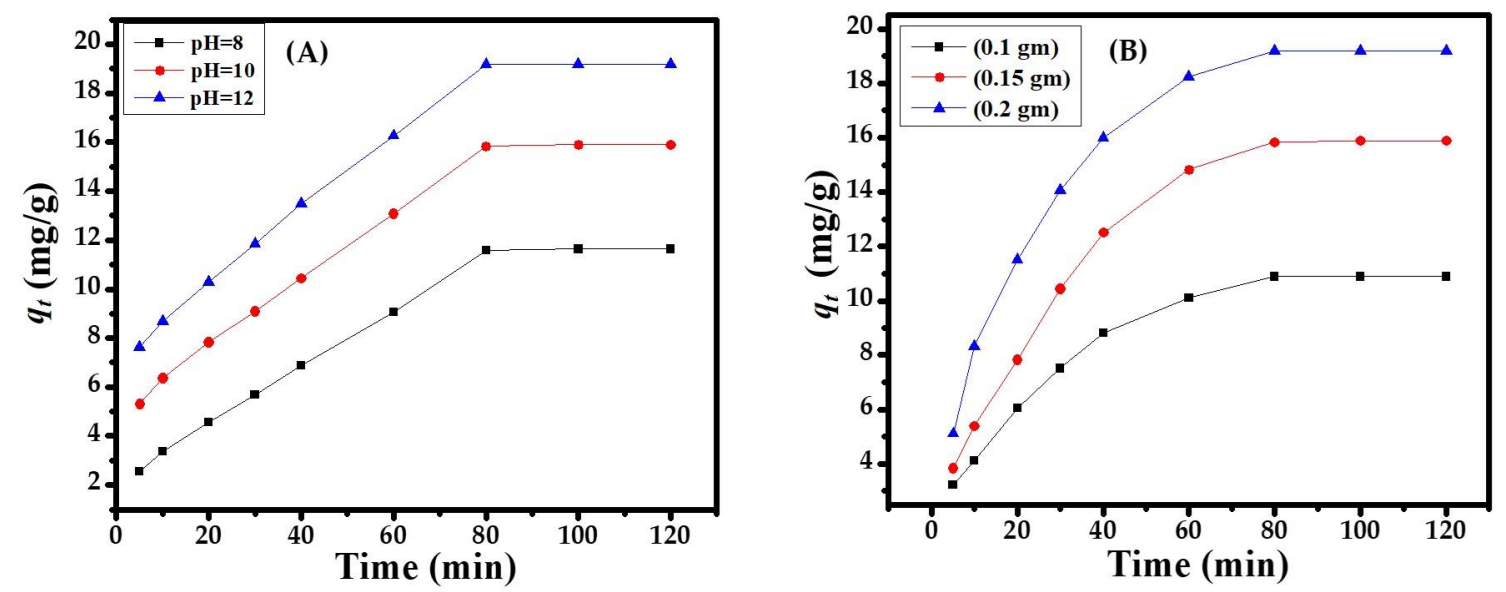

Figure 3. (A) Effect of $\mathrm{pH}$ on the adsorption of dye; (B) Effect of the adsorbent dose on dye adsorption at $\mathrm{pH} 12$.

\subsubsection{Effect of Adsorbent Dose}

The adsorbent dose was selected by its ability or regulation power to remove/degrade toxic organic compounds (MB dye). Figure 4 shows the variable dose amounts $(0.1,0.15$, and $0.2 \mathrm{~g})$. The maximum and constant adsorption capacities were obtained with $0.1 \mathrm{~g} \mathrm{CuONPs}$ at $303 \mathrm{~K}$ in alkaline medium ( $\mathrm{pH}$ 12.0). The equilibrium concentration in solution phase reached an equilibrium point at $80 \mathrm{~min}$; the amount of the adsorbent dose increases $(0.15,0.2 \mathrm{~g})$ the adsorption capacity, which decreases gradually with a minimum value Figure 3B. Eventually, the adsorbent amount has a large surface area (or active sorbent sites) that takes up the concentration of sorbate molecules. Hence, the per-unit-mass of the sorbent remains constant or increases the sorbent amount, which decreases the amount of sorbate (MB dye). Finally, the potential sites of the adsorbent amount were effective for the intended reduction in the toxic MB dye at the desirable optimization parameters Figure 3B.

\subsubsection{Effect of Concentration}

The concentration of sorbate (MB dye) ions was impressive on the sorbent surface. The sorbent capacity was determined by the uptake concentration of methyl blue dye $(51.17,102.35,128$, and $153.52 \mathrm{ppm}$ ), corresponding to the equilibrium phase. The various concentrations of the MB dye illustrated the highest sorption capacity of CuONPs (153.52 ppm) and the lowest sorption capacity (51.17 ppm) Figure 4A. Hence, increases in the concentration of the MB dye with increases in the sorption capacity at equilibrium point $(80 \mathrm{~min})$ gives a maximum and constant sorption capacity at $153.52 \mathrm{ppm}$, dose at $0.1 \mathrm{~g}, \mathrm{pH}$ at 12.0, and temperature at $303 \mathrm{~K}$. All the values are optimized and follow photocatalytic and degradation kinetics, isotherm, equilibrium isotherm, and thermo dynamics in an adequate manner.

\subsubsection{Effect of Temperature}

To study the effect of temperature on the adsorption of $\mathrm{MB}$ dye by the adsorbent from a solution of a selected pH, we selected the following temperatures: 298, 301, and $303 \mathrm{~K}$. It is clear from Figure 4B that with an increase in temperature, the adsorption increases, which indicates a chemisorption process. Perhaps this may be due to an endothermic reaction of the dye. 

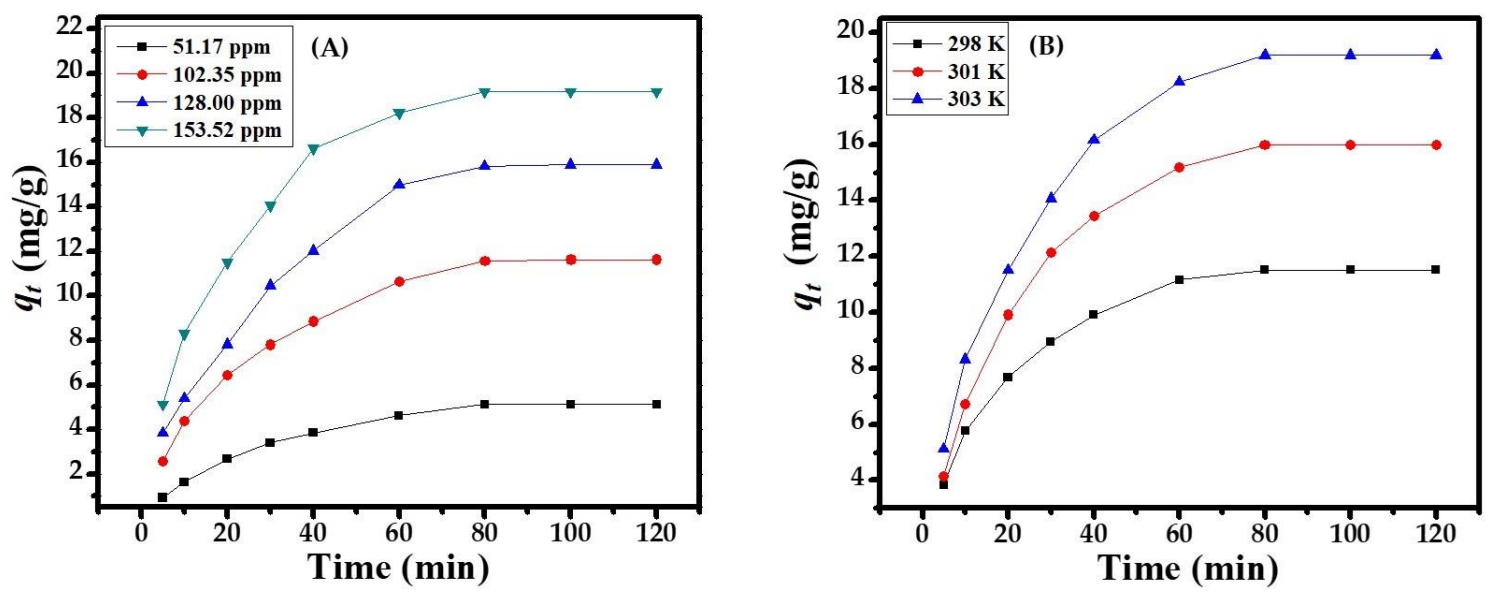

Figure 4. (A) Effect of dye concentration at pH 12; (B) Effect of dye temperature at 298, 301, and $303 \mathrm{~K}$.

\subsection{Adsorption Kinetics}

The kinetics of the pseudo-first-order equation, pseudo-second-order equation, Elovich equation, and intraparticle diffusion are best fitted with a linear regression equation. The values are summarized in Table S1, which shows that the metal ion adsorption follows the following order:

pseudo-second-order $>$ Elovich model $>$ pseudo-first-order $>$ intraparticle diffusion model

A plot of $t / q_{t}$ versus $t$ gives the value of the constant $K_{\mathrm{s}}\left(\mathrm{g} \cdot \mathrm{mg}^{-1} \cdot \mathrm{min}^{-1}\right)$; also, $q_{\mathrm{e}}\left(\mathrm{mg} \cdot \mathrm{g}^{-1}\right)$ can be calculated. The descriptive values of the pseudo-second-order kinetics are as follows: $K_{\mathrm{s}}=0.001454 \mathrm{~g} \cdot \mathrm{mg}^{-1} \cdot \mathrm{min}^{-1}, q_{\mathrm{e}}=23.5183 \mathrm{mg} \cdot \mathrm{g}^{-1}, h=1.2431 \mathrm{mg} \cdot \mathrm{g}^{-1} \cdot \mathrm{min}^{-1}, R^{2}=0.9995$. The pseudo-second-order kinetic plot for dye adsorption at a concentration of MB dye of $153.52 \mathrm{ppm}$, adsorbent dose (CuONPs) of $0.10 \mathrm{~g}, \mathrm{pH}$ of 12.0 , equilibrium at $80 \mathrm{~min}$, and temperature at $303 \mathrm{~K}$, are shown in Figure 5A-D. The value of $K_{\mathrm{f}}=0.0030 \mathrm{~min}^{-1}$ is a pseudo-first-order rate constant and $K_{\mathrm{s}}=0.0014 \mathrm{~min}^{-1}$ is a pseudo-second-order rate constant but the sorption process follows pseudo second order. The Elovich equation—the value of $\alpha\left(2.634 \mathrm{mg} \cdot \mathrm{g}^{-1} \cdot \mathrm{min}^{-1}\right)$ initial sorption rate-covers the extensive absorption sites in Table S2.
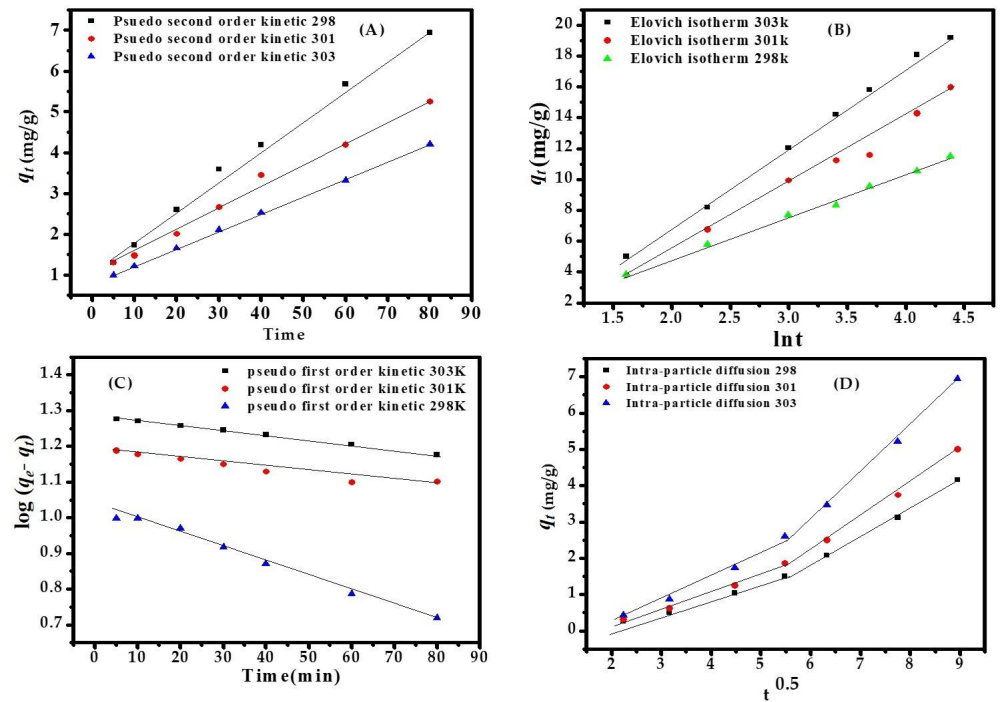

Figure 5. (A) Pseudo second order kinetic model (B) Elovich kinetic model (C) kinetic first order (D) Intrapartcle diffusion kinetic model for adsorption of MB dye at various temp eratures. 


\subsection{Adsorption Isotherm}

Adsorption properties and equilibrium parameters, commonly known as the adsorption isotherm, describe how the sorbate interacts with the sorbent surface. The complete consideration of all isotherms help to provide the information about the optimum use of the sorbent. To optimize the design of an adsorption system to organic impurities from dye solutions, it is essential to establish the most appropriate correlation for the equilibrium curve. The sorption can be analyzed via different isotherm equations, especially the Langmuir and Freundlich models, D-R, Temkin, and Hasley. The Harkins-Jura model is infrequently used. All the isotherms described above are shown in Figure 6A-F. The parameters of the isotherms are reported in Table S3 and can be presented with the following order:

Langmuir $>$ Freundlich $>$ Hasley $>$ Temkin $>$ H-J model $>$ D-R model

This can be with the dimensionless separation factor $R_{\mathrm{L}}$ :

$$
R_{L}=\frac{1}{1+K_{\mathrm{L}} C_{0}}
$$

where $K_{\mathrm{L}}$ is the Langmuir constant $\left(\mathrm{L} \cdot \mathrm{mg}^{-1}\right)$ and $C_{0}$ is the initial concentration (ppm). The value of $R_{\mathrm{L}}$ determines the isotherm to be unfavorable $\left(R_{\mathrm{L}}>1\right)$, linear $\left(R_{\mathrm{L}}=1\right)$, favorable $\left(0<R_{\mathrm{L}}<1\right)$, or irreversible $\left(R_{\mathrm{L}}=0\right)$. It has been found that the range of $R_{\mathrm{L}}$ is 0.706 to 0.899 for $153.52 \mathrm{ppm}$ at $303 \mathrm{~K}$. The adsorption energy exponentially decreases on the adsorption sites at equilibrium point $\left(K_{\mathrm{f}}=0.0 .262 \mathrm{mg}^{1-(1 / n)} \cdot \mathrm{L}^{1 / n} \cdot \mathrm{g}^{-1}\right)$ and $n=1.030$ indicates the strength of the adsorbent for favorable sorption of MB ions. The equilibrium binding constant $\left(K_{T}=0.0193\right)$, which corresponds to a maximum binding energy and heat of sorption $B 1=232.782 \mathrm{~J} / \mathrm{mol}$ ), exhibits a strong interaction between the adsorbate and adsorbent at a constant temperature.
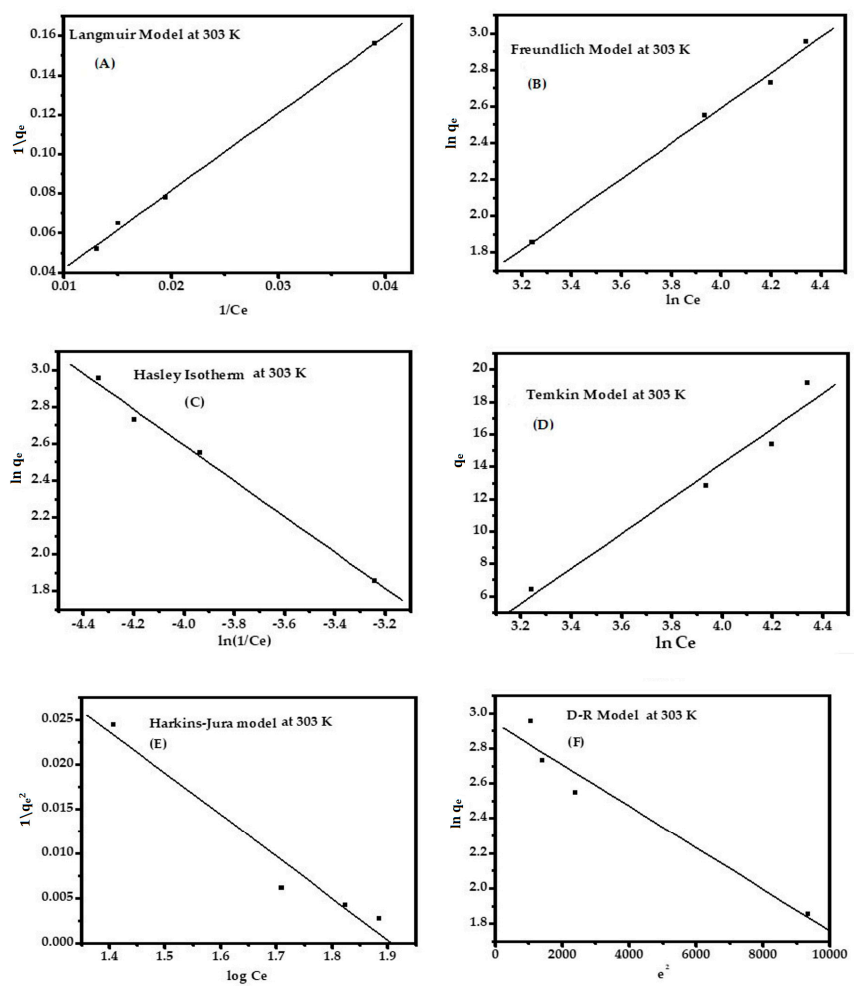

Figure 6. Different types of adsorption isotherm: Langmuir (A); Freundlich (B); Hasley (C); Temkin (D); $\mathrm{H}-\mathrm{J}(\mathbf{E})$; and D-R (F) for MB dye in $\mathrm{pH} 12.01$ at $303 \mathrm{~K}$. 


\subsection{Activation Energy}

The activation energy Ea is determined according to the Arrhenius equation: $\ln \mathrm{k}_{2}=\ln A-E \mathrm{a} / R T$. $\mathrm{A}$ is the Arrhenius constant, the value of $E$ a can be determined from the slope of $\operatorname{lnk}_{2}$ versus $1 / T$ plot (Figure 7A). From the plot, the value of Ea is $167.87 \mathrm{~kJ} \cdot \mathrm{mol}^{-1}$. The positive value means sorption process is endothermic in nature and favors sorption with an increase in temperature.
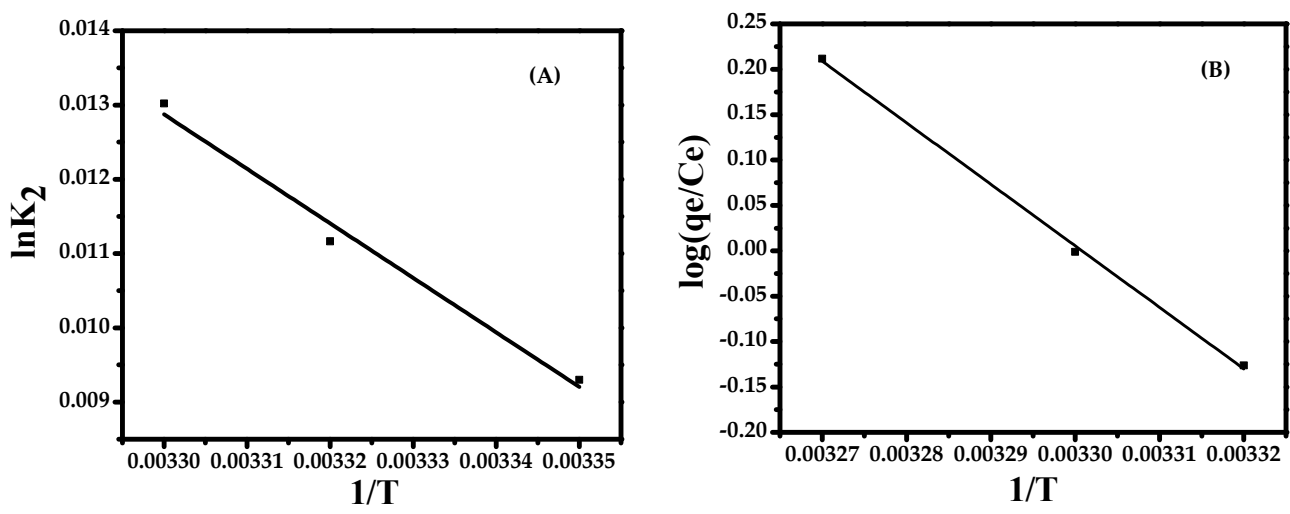

Figure 7. (A) The Arrhenius plot and (B) the van't Hoff plot.

\subsection{Thermodynamic Assessment}

Temperature dependence of the adsorption process is associated with several thermodynamic parameters. Thermodynamic considerations of the sorption process are necessary to conclude whether the process is spontaneous or not. The values of Gibbs free energy $\Delta \mathrm{G}^{\circ}$, enthalpy change $\Delta \mathrm{H}^{\circ}$, and the entropy of the adsorption $\Delta \mathrm{S}^{\circ}$, which are obtained from the slope and intercept of a plot of $\log \left(q_{\mathrm{e}} / C_{\mathrm{e}}\right)$ versus $1 / T$, are shown in Figure $7 \mathrm{~B}$.

The endothermic nature is also indicated by the increase in the amount of adsorption with an increase in temperature. The positive value of entropy and enthalpy $(129,888.183 \mathrm{~J} / \mathrm{mole}$ and $129,870.009 \mathrm{~J} / \mathrm{mole}$, respectively,) indicates that the adsorption process is endothermic in nature and has increased randomness during adsorption. The negative value of $\Delta \mathrm{G}^{\circ}(-18.1744 \mathrm{~J} / \mathrm{mol}$ at $303 \mathrm{~K})$ indicates that the reaction is spontaneous.

\subsection{ErrorAnalysis}

The error analysis suggests accurate result values and provides fine values, which differ from the deviation of actual values or true values. In this work, error analysis was performed for the equilibrium isotherm and the types of error details are described along with the isotherms in Table S4.

\section{Conclusions}

In this work, we synthesized copper oxide nanoparticles via a solution process with the use of copper nitrate hexahydrate $\left(\mathrm{Cu}\left(\mathrm{NO}_{3}\right)_{2} \cdot 6 \mathrm{H}_{2} \mathrm{O}\right)$, n-propylamine, and sodium hydroxide $(\mathrm{NaOH})$ with surfactant CTAB. The morphology of the NPs was characterized using instruments such as FE-SEM and TEM. The crystalline property of the material was examined with X-ray diffraction pattern (XRD). The obtained nanostructures are spherically shaped with an average diameter of about 10-15 nm, confirmed via TEM images. The photocatalytic performance of the copper oxide nanoparticles was analyzed via UV-visible spectroscopy; their maximum catalytic efficiency $(90.74 \%)$ for the reduction of methylene blue (MB) dye was achieved in a short time span $(80 \mathrm{~min})$. The prepared NPs were employed for the adsorption/degradation of methylene blue (MB) dye in an aqueous medium at pH 12.06. The selected conditions were confirmed via optimization methods for the degradation and adsorption process at maximum and constant adsorbent dose $(0.1 \mathrm{~g})$, concentration of MB dye (153.52 ppm), solution $\mathrm{pH}(12.06)$, temperature $(303 \mathrm{~K})$, and time ( $80 \mathrm{~min})$ and their equilibrium states. Data analysis of 
the photocatalytic degradation, kinetic equilibrium, isotherm models, and thermodynamic parameters with error analysis favors the adsorption mechanism. The reliable adsorption data demonstrate that the nanomaterial quantity $(0.1 \mathrm{~g})$ allowed the reaction (CuONPs-MB dye) to be possible at the desired optimized reaction parameters. The excellent feasibility is the main selection criteria of the CuONPs with the adsorptive species (conc. $153.52 \mathrm{ppm}$ ), activating the adsorption sites for controlled MB dye ion capture due to the maximum adsorption capacity $(350.87 \mathrm{mg} / \mathrm{g})$ and the removal efficiency in the equilibrium phase at the highest temperature $(303 \mathrm{~K})$. Additionally, the adsorption mechanism is related to behavior properties such as equilibrium adsorption kinetic models, equilibrium isotherm models, and equilibrium thermodynamic parame- ters. The kinetic adsorption provided deeper insight into the structural characteristics and the four models applied, which is the best-fit results decided from the $R^{2}$ value (0.9995), describe the adsorption mechanism following pseudo-second-order in the sorption process. The adsorption isotherm models were also selected on the $R^{2}$ value. Langmuir models express the best fit straight line graph with an excellent correlation coefficient $\left(R^{2}=0.9988\right)$ compared to the other models $(\mathrm{D}-\mathrm{R}=0.9251)$. The dimensionless separation factor $\left(R_{\mathrm{L}}\right)$ values (0.899) of less than 1 indicate the favorable chemisorption considering the MB ions are uniformly distributed on the adsorbent surface at $303 \mathrm{~K}$ temperature. The thermodynamic parameters $\left(\Delta \mathrm{G}^{\circ}\right.$, $\Delta \mathrm{H}^{\circ}, \Delta \mathrm{S}^{\circ}$ ) provide imperative information about the sorption mechanism: the adsorption reaction is spontaneous and endothermic in nature $\left(\Delta \mathrm{G}^{\circ}=-\right.$ ve while $\Delta \mathrm{H}^{\circ}, \Delta \mathrm{S}^{\circ}=+$ ve at the highest temperature $303 \mathrm{~K})$. The collection of all data $\left(\Delta \mathrm{G}^{\circ}=-18.1744, \Delta \mathrm{H}^{\circ}=129,870.009, \Delta \mathrm{S}^{\circ}=129,888.183 \mathrm{~J} / \mathrm{mole}\right)$ from the statistical analyses provide support for the sorption process. The endothermic sorption process expresses an increase in adsorption with an increase in temperature and the value of Gaussian energy $(E a=167.87 \mathrm{~J} / \mathrm{mol})$ indicates the solute's activity per molecule of adsorbate on the surface of the adsorbent. The error analysis—-such as residual root mean square error (RMSE), Chi-square test, sum of the squares of errors (SSE), average relative error (ARE), and sum of the absolute errors (SAE), average percentage errors(APE), Marquardt's percent standard deviation (MPSD)—provides various values with respect to the order of significance and addresses the balance issue of the driven sorption mechanism.

Supplementary Materials: The following are available online at http:/ /www.mdpi.com/2079-4991/8/3/134/s1, Table S1: Adsorption kinetics parameters; Table S2: Linear regression equation fit for adsorption kinetics; Table S3: Adsorption equilibrium isotherm parameters; Table S4: Error analysis for Isotherm models.

Author Contributions: F.K. designed the experiment, did the statistical, thermodynamic study, and prepared the manuscript; R.W. did the experiments for the synthesis of nanostructures, prepared the manuscript, and assessed the data. M.R. and Lu. helped in the data analysis. M.H. and R.A. supported the experiments and finalized the manuscript.

Conflicts of Interest: The authors declare no competing financial interests.

\section{References}

1. Wahab, R.; Hwang, I.H.; Kim, Y.S.; Musarrat, J.; Siddiqui, M.A.; Seo, H.K.; Tripathy, S.K. Non-hydrolytic synthesis and photo-catalytic studies of ZnO nanoparticles. Chem. Eng. J. 2011, 175, 450-457. [CrossRef]

2. Farghali, A.A.; Bahgat, M.; Enaiet Allah, A.; Khedr, M.H. Adsorption of $\mathrm{Pb}(\mathrm{II})$ ions from aqueous solutions using copper oxide nanostructures. Beni-Suef Univ. J. Basic Appl. Sci. 2013, 2, 61-71. [CrossRef]

3. El-Shobaky, G.A.; Hassan, H.M.A.; Abdel Halim, K.S.; El-Korashy, S.A.; Mohamed, S.K. Adsorption and photocatalytic degradation of methylene blue dye over $\mathrm{Pd}-\mathrm{CeO} / \mathrm{TiO}$ and $\mathrm{CuO}-\mathrm{CeO} / \mathrm{TiO}$ Catalysts. World J. Chem. 2012, 7, 11-16.

4. Chatterjee, S.; Tyagiand, A.K.; Ayyub, P. Efficient photocatalytic degradation of Rhodamine B dye by aligned arrays of self-assembled a hydrogen titanate nanotubes. J. Nanomater. 2014, 2014, 36. [CrossRef]

5. Wahab, R.; Hwang, I.H.; Kim, Y.S.; Shin, H.S. Photocatalytic activity of zinc oxide micro-flowers synthesized via solution method. Chem. Eng. J. 2011, 168, 359-366. [CrossRef]

6. Wahab, R.; Khan, F.; Ahmad, N.; Shin, H.S.; Musarrat, J.; Al-Khedhairy, A.A. Hydrogen adsorption properties of nano-and microstructures of ZnO. J. Nanomater. 2013, 2013, 101. [CrossRef]

7. Mishra, Y.K.; Adelung, R. ZnO tetrapod materials for functional applications. Mater. Today 2017. [CrossRef] 
8. Mekatel, E.H.; Amokrane, S.; Aid, A.; Nibou, D.; Trari, M. Adsorption of methyl orange on nanoparticles of a synthetic zeolite NaA/CuO. C. R. Chim. 2015, 18, 336-344. [CrossRef]

9. Shaheed, M.A.; Hussein, F.H. Adsorption of reactive black 5 on synthesized titanium dioxide nanoparticles: Equilibrium isotherm and kinetic studies. J. Nanomater. 2014, 2014, 3. [CrossRef]

10. Li, C.; Dong, Y.; Yang, J.; Li, Y.; Huang, C. Modified nano-graphite $/ \mathrm{Fe}_{3} \mathrm{O}_{4}$ composite as efficient adsorbent for the removal of methyl violet from aqueous solution. J. Mol. Liq. 2014, 196, 348-356. [CrossRef]

11. Pung, S.Y.; Lee, W.P.; Aziz, A. Kinetic study of organic dye degradation using ZnO particles with different morphologies as a photocatalyst. Int. J. Inorg. Chem. 2012, 2012, 608183. [CrossRef]

12. Gupta, V.K.; Jain, R.; Mittal, A.; Saleh, T.A.; Nayak, A.; Agarwal, S.; Sikarwar, S. Photo-catalytic degradation of toxic dye amaranth on $\mathrm{TiO}_{2} / \mathrm{UV}$ in aqueous suspensions. Mater. Sci. Eng. C 2012, 32, 12-17. [CrossRef] [PubMed]

13. Shu, J.; Song, C.; Xia, H.; Zhang, L.; Peng, J.; Li, C.; Zhang, S. Copper loaded on activated carbon as an efficient adsorbent for removal of methylene blue. RSC Adv. 2017, 7, 14395-14405. [CrossRef]

14. Liang, Z.; Zhao, Z.; Sun, T.; Shi, W.; Cui, F. Enhanced adsorption of the cationic dyes in the spherical $\mathrm{CuO} /$ meso-silica nano composite and impact of solution chemistry. J. Colloid Interface Sci. 2017, 485, 192-200. [CrossRef] [PubMed]

15. Simeonidis, K.; Mourdikoudis, S.; Kaprara, E.; Mitrakas, M.; Polavarapu, L. Inorganic engineered nanoparticles in drinking water treatment: A critical review. Environ. Sci. Water Res. Technol. 2016, 2, 43-70. [CrossRef]

16. Wahab, R.; Khan, S.T.; Dwivedi, S.; Ahamed, M.; Musarrat, J.; Al-Khedhairy, A.A. Effective inhibition of bacterial respiration and growth by $\mathrm{CuO}$ microspheres composed of thin nano sheets. Colloids Surf. B Biointerfaces 2013, 111, 211-217. [CrossRef] [PubMed]

17. Sathyamoorthy, R.; Mageshwari, K. Synthesis of hierarchical CuO microspheres: Photocatalytic and antibacterial activities. Phys. E Low-Dimens. Syst. Nanostruct. 2013, 47, 157-161. [CrossRef]

18. Luo, L.B.; Wang, X.H.; Xie, C.; Li, Z.J.; Lu, R.; Yang, X.B.; Lu, J. One-dimensional CuO nanowire: Synthesis, electrical, and optoelectronic devices application. Nanoscale Res. Lett. 2014, 9, 637. [CrossRef] [PubMed]

19. Barreca, D.; Comini, E.; Gasparotto, A.; Maccato, C.; Sada, C.; Sberveglieri, G.; Tondello, E. Chemical vapor deposition of copper oxide films and entangled quasi 1D nano architectures as innovative gas sensors. Sens. Actuators B 2009, 141, 270-275. [CrossRef]

20. Ma, Y.; Jang, H.; Kim, S.J.; Pang, C.; Chae, H. Copper-Assisted direct growth of vertical graphene nanosheets on glass substrates by low-temperature plasma-enhanced chemical vapour deposition process. Nanoscale Res. Lett. 2015, 10, 308. [CrossRef] [PubMed]

21. Ying, Z.; Lam, F.L.Y.; Xijun, H.; Zifeng, Y. Fabrication of copper nanorods by low-temperature metal organic chemical vapor deposition. Chin. Sci. Bull. 2006, 51, 2662-2668.

22. Outokesh, M.; Hosseinpour, M.; Ahmadi, S.J.; Mousavand, T.; Sadjadi, S.; Soltanian, W. Hydro thermal Synthesis of $\mathrm{CuO}$ Nanoparticles: Study on effects of operational conditions on yield, purity, and size of the nanoparticles. Ind. Eng. Chem. Res. 2011, 50, 3540-3554. [CrossRef]

23. Kayani, Z.N.; Umer, M.; Riaz, S.; Naseem, S. Characterization of Copper oxide nanoparticles fabricated by the Sol-Gel Method. J. Electron. Mater. 2015, 44, 3704-3709. [CrossRef]

24. Saravanan, V.; Shankar, P.; Mani, G.K.; Rayappan, J.B.B. Growth and Characterization of spray pyrolysis deposited copper oxide thin films: Influence of substrate and annealing temp eratures. J. Anal. Appl. Pyrolysis 2015, 111, 272-277. [CrossRef]

25. Ashok, A.; Kumar, A.; Bhosale, R.R.; Saleh, M.A.H.; van den Broeke, L.J.P. Cellulose assisted combustion synthesis of porous $\mathrm{Cu}-\mathrm{Ni}$ nanopowders. RSC Adv. 2015, 5, 28703-28712. [CrossRef]

26. Ramyadevi, J.; Jeyasubramanian, K.; Marikani, A.; Rajakumar, G.; Rahuman, A.A. Synthesis and antimicrobial activity of copper nanoparticles. Mater. Lett. 2012, 71, 114-116. [CrossRef]

27. Misra, S.K.; Dybowska, A.; Berhanu, D.; Luoma, S.N.; Jones, E.V. The complexity of nanoparticle dissolution and its importance in nanotoxicological studies. Sci. Total Environ. 2012, 438, 225-232. [CrossRef] [PubMed]

28. Nowacka, M.; Sikorska, A.M.; Chrzanowski, Ł.; Ambrożewicz, D.; Rozmanowski, T.; Myszka, K.; Czaczyk, K.; Bula, K.; Jesionowski, T. Electrokinetic and bioactive properties of $\mathrm{CuO} \cdot \mathrm{SiO}_{2}$ oxide composites. Bioelectrochemistry 2012, 87, 50-57. [CrossRef] [PubMed]

29. World Health Organization (WHO). Environmental Health Criteria; No. 200, Lead.-CH-1211; WHO: Geneva, Switzerland, 1998. 
30. Bladin, P.F. Azo dyes and the blood-brain barrier: Robert Aird's novel concept in chronic neurological disease (1903-2000). J. Clin. Neurosci. 2014, 21, 33-39. [CrossRef] [PubMed]

31. Mpousisa, S.; Thysiadisa, S.; Avramidis, N.; Katsamakas, S.; Efthimiopoulos, S.; Sarlia, V. Synthesis and evaluation of gallocyanine dyes as potential agents for the treatment of Alzheimer's disease and related neurodegenerative tauopathies. Eur. J. Med. Chem. 2016, 108, 28-38. [CrossRef] [PubMed]

32. Wahab, R.; Khan, F.; Aldahmash, B.A.; Al-Khedhairy, A.A. Statistical Analytical determination of Miniature Zinc Oxide Nanoclusters for Photodegradation of Methylene Red Dye. Nanosci. Nanotechnol. Lett. 2017, 9, 1-7. [CrossRef]

33. Wahab, R.; Khan, F.; Lutfullah; Al-Khedhairy, A.A. Photocatalytic activity and statistical determination of ball-shaped zinc oxide NPs with methylene blue dye. Inorg. Nano-Met. Chem. 2017, 47, 536-542. [CrossRef]

34. Wahab, R.; Khan, F.; Mishra, Y.K.; Musarrat, J.; Al-Khedhairy, A.A. Antibacterial studies and statistical design set dataof quasi zinc oxide nanostructures. RSC Adv. 2016, 6, 32328-32339. [CrossRef]

35. Wahab, R.; Khan, F. Role of Nanostructures for Anti-proliferation of Bacteria and their Quantitative Study Validated by Statistical Analysis. J. Pharm. Innov. 2014, 9, 282-290. [CrossRef]

36. Wahab, R.; Khan, F. Wet chemically synthesized catalytic nanorods for the deactivation of thymol blue and their statistical analytical applications. Ceram. Int. 2015, 41, 3722-3730. [CrossRef]

37. Sanjini, N.S.; Winston, B.; Velmathi, S. Effect of Precursors on the Synthesis of CuO Nanoparticles Under Microwave for Photocatalytic Activity Towards Methylene Blue and Rhodamine B Dyes. J. Nanosci. Nanotechnol. 2017, 17, 495-501. [CrossRef]

38. Xu, J.; Yuvaraja, G.; Zhang, W. Application of chitosan/poly(vinyl alcohol)/CuO (CS/PVA/CuO) beads as an adsorbent material for the removal of $\mathrm{Pb}$ (II) from aqueous environment. Colloids Surf. B Biointerfaces 2017, 149, 184-195.

39. Raizada, A.; Ganguly, D.; Mankad, M.M.; Krishna, R.H.; Nagabhushana, B.M. A Highly Efficient Copper Oxide Nanopowder for Adsorption of Methylene Blue Dye from Aqueous Medium. J. Chem. Eng. Res. 2014, 2, 249-258.

40. Shaibu, S.E.; Adekola, F.A.; Adegoke, H.I.; Ayanda, O.S. A Comparative Study of the Adsorption of Methylene Blue onto Synthesized Nanoscale Zero-Valent Iron-Bamboo and Manganese-Bamboo Composites. Materials 2014, 7, 4493-4507. [CrossRef] [PubMed]

41. Gunasekar, V.; Ponnusami, V. Kinetics, Equilibrium, and Thermodynamic Studies on Adsorption of Methylene Blue by Carbonized Plant Leaf Powder. J. Chem. 2013, 2013, 415280. [CrossRef]

42. Pandian, P.; Arivoli, S.; Marimuthu, V.; Regis, A.P.P. Kinetic, Thermodynamic and Isotherm Studies on the Removal of Methylene Blue Dye using Acid Activated Ipomoea carnea. Int.J. Revolut. Sci. Humanit. 2013, 2, 19-29.

43. Hadia, M.; Samarghandia, M.R.; McKay, G. Equilibrium two-parameter isotherms of acid dyes sorption by activated carbons: Study of residual errors. Chem. Eng. J. 2010, 160, 408-416. [CrossRef]

44. Hanna, O.T.; Sandall, O.C. Computational Methods in Chemical Engineering; Prentice-Hall International: Upper Saddle River, NJ, USA, 1995.

45. Tsai, S.C.; Juang, K.W. Comparison of linear and non-linear forms of isotherm models for strontium sorption on a sodium bentonite. J. Radioanal. Nucl. Chem. 2000, 3, 741-746. [CrossRef]

46. Kapoor, A.; Yang, R.T. Correlation of equilibrium adsorption data of condensable vapours on porous adsorbents. Gas Sep. Purif. 1989, 3, 187-192. [CrossRef]

47. Ng, J.C.Y.; Cheung, W.H.; McKay, G. Equilibrium studies of the sorption of $\mathrm{Cu}(\mathrm{II})$ ions onto chitosan. J. Colloid Interface Sci. 2002, 255, 64-74. [CrossRef] [PubMed]

48. Marquardt, D.W. Analgorithm for least-squares estimation of nonlinear parameters. J. Soc. Ind. Appl. Math. 1963, 11, 431-441. [CrossRef]

49. Langmuir, I. The adsorption of gases on plane surfaces of glass, mica, and platinum. J. Am. Chem. Soc. 1918, 40,1361-1403. [CrossRef]

50. Freundlich, H.Z. Over the adsorption in solution. J. Phys. Chem. 1906, 57A, 385-397.

51. Temkin, M.J.; Pyzhev, V. Kinetics of ammonia synthesis on promoted iron catalysts. Acta Physiochim. URSS 1940, 12, 217-222.

52. Dubinin, M.M.; Radushkevich, L.V. The equation of the characteristic curve of activated charcoal. Doklady Akademii Nauk SSSR 1947, 55, 327-329. 
53. Harkins, W.D.; Jura, E.J. The decrease of free surface energy as a basis for the development of equations for adsorption isotherms; and the existence of two condensed phases in films on solids. J. Chem. Phys. 1944, 12, 112-113. [CrossRef]

54. Halsey, G. Physical adsorption on nonuniformsurfaces. J. Chem. Phys. 1948, 16, 931-937. [CrossRef]

55. Lagergren, S. About the theory of so-called adsorption of soluble substances. Handlingar 1898, 24, 1-39.

56. Ho, Y.S.; Mckay, G. The kinetics of sorption of basic dyes from aqueous solution by sphagnum moss peat. Can. J. Chem. Eng. 1998, 76, 822-827. [CrossRef]

57. Yakout, S.M.; Elsherif, E. Batch kinetics, isotherm and thermodynamic studies of adsorption of strontium from aqueous solutions onto low cost rice-straw based carbon. Carbon Sci. Techol. 2010, 1, 144-153.

58. Weber, J.W.J.; Morris, J.C. Kinetics of Adsorption of Carbon from Solution. J. Sanit. Eng. Div. Am. Soc. Civ. Eng. 1963, 89, 31-60.

59. Zhang, X.; Sun, S.; Lv, J.; Tang, L.; Kong, C.; Song, X.; Yang, Z. Nanoparticle-aggregated CuO nano ellipsoids for high-performance non-enzymatic glucose detection. J. Mater. Chem. A 2014, 2, 10073-10080. [CrossRef]

60. Li, X.; Li, C.; Akihiro, Y.; Hao, X.; Zuo, Z.; Wang, Z.; Abudula, A.; Guan, G. Facile fabrication of CuO microcube@ $\mathrm{Fe}-\mathrm{Co}_{3} \mathrm{O}_{4}$ nanosheet array as a high-performance electrocatalyst for the oxygen evolution reaction. J. Mater. Chem. A 2017, 5, 21740-21749. [CrossRef]

61. Zaman, S.; Zainelabdin, A.; Amin, G.; Nour, O.; Willander, M. Efficient catalytic effect of CuO nano structures on the degradation of organic dyes. J. Phys. Chem. Solids 2012, 73, 1320-1325. [CrossRef]

(C) 2018 by the authors. Licensee MDPI, Basel, Switzerland. This article is an open access article distributed under the terms and conditions of the Creative Commons Attribution (CC BY) license (http://creativecommons.org/licenses/by/4.0/). 